ISBN 978-81-933894-1-6

International Conference on Arts, Social Sciences, History and Interdisciplinary Studies

(ASSHIS-2017)

Kyoto (Japan) April 20-21, 2017

\title{
Buying Behavior of Employees in Toyota Tsusho Forklift (Thailand) Company Limited for Personal Cars
}

\author{
Dr. Watchara Yeesoontes ${ }^{1}$, Wachiraphorn Woraphong ${ }^{2}$ \\ ${ }^{1}$ Research Advisor, Lecturer in MBA Program, Postgraduate School of Business Administration Kasembundit \\ University, Bangkok \\ ${ }^{2}$ Researcher, Student in MBA Program, Postgraduate School of Business Administration Kasembundit \\ University, Bangkok \\ watchara.yee@kbu.ac.th
}

\begin{abstract}
The goals of this study are to determine consumer behavior and marketing mix on selecting an automobile. The samplings were 220 employees at Toyota Tuso Forklift Co., Ltd., Thailand by using a check list and rating scale questionnaire as a tool. Statistical application used for this study was percentage, mean, standard deviation, Chi-Square, and regression analysis.

The basis of the results of this study, it can be concluded that most of the respondents were males, age between 31-45 years old, single marriage status, bachelor degree graduated or equivalent, monthly income more than 20,000 baht, selected an appropriated automobile, price over 700,000 baht by leasing, family influent in selection decision, marketing mix were the most important factor in selecting an automobile, and service after sale, respectively. The hypothesis testing indicated that personal different would not affect consumer behavior and marketing mix on selecting an automobile. However, factors of marketing mix, post purchased, well automobile designed, durable, dependable, and reputable brand names effected consumer behavior and marketing mix on selecting an automobile at statistic significant 0.05 level.

Recommendations from this study were that automakers should design automobile with elegant style, safety standard, energy saver, environment friendly, post purchase or service after sale, and variety of designs and models to appeal to consumer.
\end{abstract}

\section{Background and Significance of the Problem}

Cars play important role in our lives. It could be regarded as $5^{\text {th }}$ necessity of people's lives apart from food, clothing, shelter, and medicine. Car is a mode of transport which makes travelling faster and more comfortable. In addition, it represents social status and taste of owners just like accessories. Nowadays cars are gaining more popularity with various brands, designs, and features that respond to consumers' needs. Car business is expanding rapidly and competition is very high. Manufacturers try to develop new models to sell in the market to serve customer's needs as best as they can. Further, government policy supports car manufacturers to export to overseas markets. Local needs for cars continue to play important role since some group of consumers prefers modernity and want to purchase cars which are popular in the market. However, car reservation in the $36^{\text {th }}$ Bangkok Motor Show in March 2015 for 12 days was 37,027 units comparing to 39,415 units in the year 2014 (Grand Prix International Public Co., Ltd. , the organizer of the event). The total difference of 2,388 units 
indicated that although political situation in Thailand is not stable, Thai consumers still pay attention to their $5^{\text {th }}$ necessity of life significantly.

Current situation where Thailand is in economic recession, people have to be careful on their spending. However, some groups of consumers are earning income that makes them feel comfortable to spend according to their preference. Personal cars are good choice for consumers as can be seen from the data of newly registered cars in Thailand 623,250 units in year 2014 and 540,852 units in year 2015 (Transportation Statistics Planning Division). The information reveals that consumers' needs for cars are continuously growing regardless of domestic economy or political situation. Car manufacturers continue to move forward in development of their products to be modern, powerful, and several choices for consumers' best selection.

The above reasons made the researcher interested in studying the buying behavior and marketing mix that affects buying decision of employees in Toyota Tsusho Forklift (Thailand) Co., Ltd. Amata Nakorn Branch for personal cars. Findings shall be applied as supporting information for marketing plan for sales of personal cars according to consumers' needs.

\section{Objectives}

1. To study buying behavior for personal car.

2. To evaluate marketing mix factors' influence on buying behavior for personal car.

\section{Scope of Study}

This research deals with consumer behavior and marketing mix factors (product, price, place, and promotion) and their influences on buying behavior.

Population of this research is 499 employees of Toyota Tsusho Forklift (Thailand) Co., Ltd. Amata Nakorn Branch from which 220 samples are drawn.

Variables consist of:

Independent variables are demographic factors (gender, age, status, education, and income) and marketing mix factors (product, price, place, and promotion)

Dependent variables is buying behavior of employees in Toyota Tsusho Forklift (Thailand) Co., Ltd. for personal cars

Time period for the study is between January-March 2016.

\section{Benefits of the Study}

1. To realize buying behavior for personal cars.

2. To identify marketing mix factors that affect customers' choices of personal cars.

3. To find guidelines for car selling businesses and to facilitate their marketing planning.

\section{Conceptual Framework}

The research on buying behavior of employees in Toyota Tsusho Forklift (Thailand) Co., Ltd. for personal cars aims at studying employees' buying behavior and evaluating marketing mix factors that influence purchasing decision. Variables assigned by the researcher are independent variable and independent variable. Independent variables consist of gender, age, status, education, and income as well as product, price, place, and promotion. Dependent variable is buying behavior of employees in Toyota Tsusho Forklift (Thailand) Co., Ltd. for personal cars. The study will identify relationship between the two types of variables. 


\section{Data Used in the Research}

This research has been designed to acquire information according to the following objectives.

1. Primary data is obtained from questionnaire distributed to 220 samples of employees in Toyota Tsusho Forklift (Thailand) Co., Ltd. Data from this source is then assessed by computer program for statistics.

2. Secondary data is acquired through documentary research from such sources as textbooks, documents, articles, publications, books, journals, as well as previous researches to enhance completeness of this study.

Tool used in this research is questionnaire for data collection which is created by the researcher in the following steps.

1. Search from document and related studies to use as outline for questionnaire/interview design.

2. Structure of questionnaires composes of 4 important parts.

- Part1 involves personal data such as gender, age, income, and education.

- Part2 contains 6 checklist questions about buying behavior for personal cars.

- Part3 includes Likert's 5-level rating scale questions about marketing mix factors that influence buying behavior for personal cars.

- Part4 contains open-ended questions asking for opinion and suggestions of the questionnaire respondents.

\section{Data Collection Method}

The researcher collected data as follows.

1. Data from different sources such as textbooks, documents, and results of other related studies.

2. Data from questionnaires is filled and returned by the target samples, checked for completion and appropriateness for analysis.

\subsection{Data Assessment and Analysis}

Data acquired from questionnaires/interview was then assessed by the use of computer program for Percentage and Mean. Microsoft Excel was used to create Pie charts and Bar charts with explanations. The results shown in charts were then presented for analysis according to characteristics of variables.

\subsection{Statistics Used for Data Analysis}

For descriptive Statistics, data was analyzed to find Percentage and Mean to explain demographic factors of the samples and variables.

Inferential Statistics was used to test hypothesis. They include Regression Analysis, Crosstabs analysis using Chi-Square.

\section{Research Findings}

Results of the study on buying behavior of employees in Toyota Tsusho Forklift (Thailand) Co., Ltd. for personal cars can be concluded as follows.

\subsection{Conclusion on Demographic Data (Answer to objective No.1)}

From total number of 220 samples, most samples are male (52.30\%), age 31-45 years (48.10\%), single $(58.20 \%)$, graduated bachelor's degree or equivalent (78.20\%), and earning more than 20,000 Baht per month $(44.50 \%)$.

\subsection{Conclusion of Buying Behavior for Personal Cars.}

From total 220 respondents it was found that employees of Toyota Tsusho Forklift (Thailand) Co., Ltd. mostly choose to buy personal cars because of suitability for use $55.90 \%$, design of the cars $45.50 \%$, using the 
budget above 700,001 Baht 35.50\%, family has influence in the buying decision $75.50 \%$, making the buying decision with the cheapest dealer $51.40 \%$, and paying through leasing $65.90 \%$.

\subsection{Conclusion about Marketing Mix Factors (Answer to objective No. 2)}

From total 220 respondents it was found that employees of Toyota Tsusho Forklift (Thailand) Co., Ltd., results from bar charts analysis can be concluded as follows.

Product. The study found that overall mean consists of quality and safety standard in the highest level. Design, durability, continuous development, reputation and image of the manufacturer, recognized brand, and modernity are in high level respectively.

Price. The study found that overall mean consists of reasonable price with the quality, maintenance cost is not high, price is not high comparing to competitors, and resale price is high are in high level respectively.

Place. The study found that overall mean consists of standard and credibility of the showroom \& service center, location is easy to access, and number of branches \& service centers are in high level respectively.

Promotion. The study found that overall mean consists of after-sale service is in the highest level, promotion on interest rate, advertisement through different types of media, and activities \& exhibitions are in high level respectively.

\section{Discussion}

The study on buying behavior for personal cars can be explained by the researcher as follows.

For product, overall mean is in high level which is in accordance with the study of Siwali Intharawat (2012) which was about factors affecting buying decision for small size personal cars in Chiang Mai Province and found that product was in high level of measurement.

For price, overall mean is in high level which is similar to the study of Siwali Intharawat (2012) which was about factors affecting buying decision for small size personal cars in Chiang Mai Province and found that price was in high level of measurement.

For place, overall mean is in high level which is similar to the study of Siwali Intharawat (2012) which was about factors affecting buying decision for small size personal cars in Chiang Mai Province and found that place was in high level of measurement.

For promotion, overall mean is in high level which is similar to the study of Siwali Intharawat (2012) which was about factors affecting buying decision for small size personal cars in Chiang Mai Province and found that promotion was in high level of measurement.

Demographic factors i.e. gender, age, status, education level, and income have influences on buying decision for personal cars. This is similar to the research of Phimonthip Premsirisak (2009) which studied about factors related to buying decision of personal cars for retired consumers. It was found that gender, age, status, education level, and income have effects on the buying decision.

Marketing mix factors i.e. product, price, place, and promotion have positive relationship with buying behavior for personal cars. This finding is similar to the study of Somchai Janphaisri (2010) who studied about marketing factors that are related to buying decision for personal car brand Toyota of workers in Navanakorn Industrial Estate. The study found that product, price, place, and promotion have positive relationship with the buying decision.

\section{Recommendation}

From the study on buying behavior for personal cars, the researcher has notable suggestions as follows.

1. For product, it was found that the buying behavior focuses on design and durability of the product. Therefore, car manufacturers should develop the design of cars to be energy saving and environmental friendly to match with government policy and emphasize on safety. 
2. For promotion, it was found that after-sale service is the most important thing to be paid attention to. Therefore, car manufacturers should focus on after-sale service as a persuasion for car buyers. Fast service, time saving, and readiness of the team to take care customers in case of emergency should be maintained.

\section{References}

[1] Chotphat Sirichartchai. (2015). Factors Affecting Buying Behavior for Honda City CNG. Independent Study. Graduate School. Kasem Bundit University.

[2] Grand Prix International Public Co., Ltd. Organizer of $36^{\text {th }}$ Bangkok International Motor Show between March $25^{\text {th }}$ April $5^{\text {th }}, 2015$

[3] Jakrit Kluaythes. (2014). Factors Affecting Buying Decision for Eco Car in Bangkok Area. Independent Study. Graduate School. Kasem Bundit University.

[4] Kulkanya Pusapabutr. (2007). Factors Affecting Cars Buying Behavior in Bangkok. Managerial Economy. Srinakharinwirot University.

[5] Phimonthip Premsirisak. (2009). Factors that Affect Buying Decision for Personal Cars of Retired Consumers. MBA. General Business Management. Rangsit University.

[6] Siriwan Serirat. (1995). Modern Marketing Management. Bangkok: Thammasan Printing House Company Limited.

[7] Siriwan Serirat. (1996). Organization and Management. Bangkok: Education Development Publisher.

[8] Siriwan Serirat. (1998). Consumer Behavior. Basic Volume. Bangkok: Visit Phattana Co., Ltd.

[9] Siriwan Serirat. (2003). Consumer Behavior Model. Revision Edition Year 2003, Bangkok. Thammasan Printing Co., Ltd.

[10] Siwali Intharawat .(2012). Factors Affecting Buying Behavior for Small Size Personal Cars in Mueang Chiang Mai Province. Master of Arts. Chiang Mai University

[11] Somchai Janphaisri. (2010). Marketing Factors that have Relations with Buying Behavior for Personal Cars Brand Toyota of Workers in Navanakorn Industrial Estate. MBA. Easten Asia University.

[12] Thongchai Santiwong. (1994). Consumer Behavior. Bangkok: Thaiwattanaphanich. 